\title{
Wisdom Applied: The Secret Sauce That Has Allowed Me Already to Have Achieved Immortality
}

Robert J. Sternberg

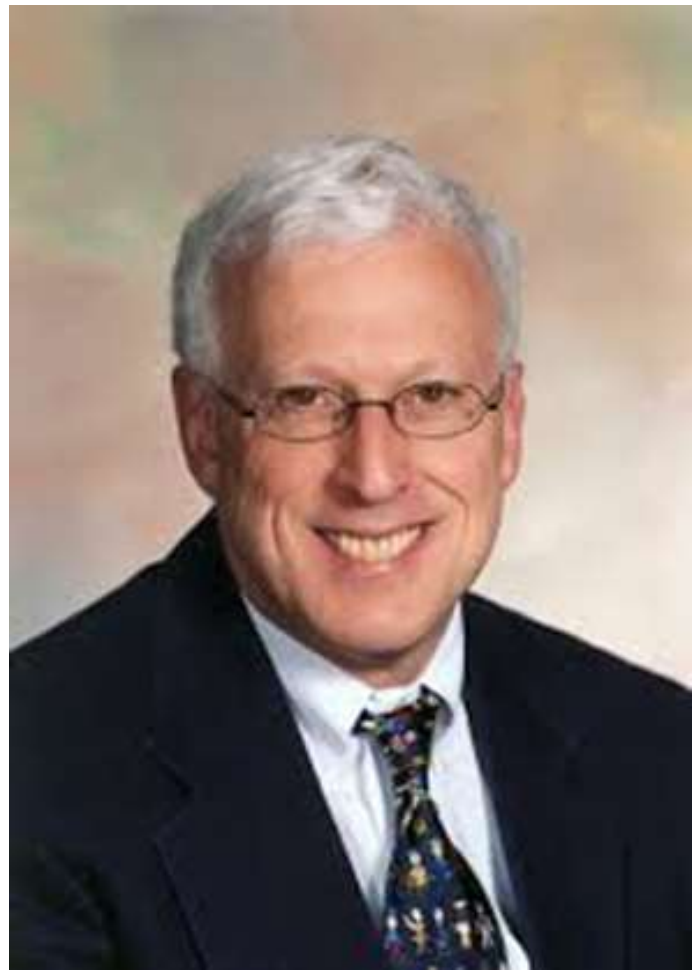

His name was Dennis. I don't remember what he looked like, except that he was older and bigger than I was. I was 3 years old and of just average size. I was walking in back of our house on Tuxedo Parkway in Newark, New Jersey. All of a sudden, Dennis came rushing at me with a clothespin in his hand. I didn't know what his intentions were, but they didn't look good. I started running, but he was faster than I was, caught up to me, and hit me on the side of the face with the clothespin. I did not know then nor do I know today why he did this. I scarcely knew the kid. I do know I still have a tiny scar on the side of my face from where he hit me.

That's my first memory. It's not what anyone would want to have as a first memory. My son Seth has told me that his first memory is of his being in my arms at night, with my dancing him to sleep with music in the background. Certainly that is a better first memory than mine. But one does not really get to choose one's first memory. (Here and elsewhere, I will note some lessons I have learned in life by a bulleted and bolded sentence or two.)

\section{* In one's life and one's career, expect the unexpected.}

The little tragedy with Dennis was about as unexpected as any event in life can be. In the 63 years I have lived since the Dennis event, I have gotten used to the fact that life-altering events-positive and negativeoften happen suddenly and seemingly senselessly. I've had papers rejected that I was almost certain would be accepted and I've had papers accepted that I thought scarcely deserved to see the light of day. I had the top possible rating on a grant proposal and it wasn't funded. I had a highly successful research project and it wasn't renewed. I received awards and honorary 
doctorates that seemed just to come out of the blue. We lost twins at birth for absolutely no good reason and then were blessed with triplets, something I would have thought was close to impossible for us. There is a Woody Allen saying that "If you want to make God laugh, tell Him about your plans." That certainly has been my experience in life.

\section{Expect the unexpected and do not let it rattle you or throw you off your course.}

When I was 3 years old, we moved out of Newark to Maplewood, a suburb of Newark. I attended the local public schools through the end of high school. I apparently did poorly on the reading-readiness test and that was just the beginning of my struggles with tests. When I was going to elementary school, in the late 1950s and early 1960s, the school system had a habit of administering group IQ tests to its students every year or two. I was deathly afraid of these tests-or maybe it was anxiety about what seemed to be the very scary lady (school psychologist) who administered them. I panicked every time and apparently my scores showed it. When I was in sixth grade the school sent me back to a fifth-grade classroom to take an easier test that the authorities thought would be more at my ability level. As a result of my low scores on standardized intelligence tests, my teachers thought I was stupid; I thought I was stupid; I did stupid work; my teachers were happy I did stupid work; I was happy they were happy; and everyone was quite happy.

\section{Self-fulfilling prophecies can make or break careers-and lives.}

In my case, the self-fulfilling prophecy was on the way to breaking my career as a student. I was one of the lucky ones. I had a fourth-grade teacher, Mrs. Alexa, who believed that there is more to a person than an IQ test score, so in fourth grade I went from being a mediocre student to being an A student. But not everyone is so lucky.
You might think that what happened to me is a product of when I grew up. On the contrary, nothing has changed. My son Seth, now 37 years old and a highly successful serial entrepreneur, is one generation behind me. He was on the same road. He was given a reading readiness test on his first day of school in a new district, with a new home, with a new teacher, with new children in the classroom-well, you get the idea. He muffed it. They put him in the lowest reading group, even though he had been in the top reading group in his former school. It took them a long time to realize that they had made a mistake, because so often teachers get what they expect. Seth later graduated from Yale.

My daughter Sara's nursery school teacher wanted to keep her back a year for lack of social skills. My wife at the time and I didn't buy it. Sara graduated from Yale, too, and is now a law professor at Duke.

Lest you think self-fulfilling prophecies ended in Seth and Sara's generation, consider my wife Karin's and my triplets, Samuel, Brittany, and Melody, now age 5. They were born prematurely, as triplets almost always are, and with the usual challenges of triplets. They also are being raised in a bilingual household. At 3 years of age, they were diagnosed by a licensed psychologist as falling on the autism spectrum. Today they are chatting away, fluent in two languages, with excellent social skills. So five out of five children plus their father have been diagnosed as being able to expect a life of doom and gloom. Selffulfilling prophecies are alive and, well, waiting to harm you and your children if you don't intervene!

\section{You will have a lot of so-called experts tell you how things should be and have to be. If your gut tells you that they are wrong, be skeptical-very skeptical.}

In grade 7 , when I was 13 years old, I decided the time had come to figure out the whole IQ test business. So I did a science project on the development of the mental 
test. Part of my project involved my creating my own test and part of it involved giving classmates the Stanford-Binet Intelligence Scales, which I found in the adult section of the library in my town. When the school authorities discovered what I was doing, I got royally rebuked and was warned never to bring the test into school again.

Fortunately, my science teacher, Mr. Adams, stood up for me, or I might have been suspended or worse. The main lesson I was taught was not about doing what you truly want to do, but rather about doing something else. Find your passion, not someone else's.

\section{Never give an IQ test to someone with whom you want to become romantically involved.}

Okay, you probably never planned to give an IQ test to a potential romantic partner, but one never knows. I thought giving a potential girlfriend an IQ test might get her interested in me. I obviously was not at the peak of my social intelligence. Anyway, it didn't work, although I must say the girl scored super-well on the test. Although the romance never happened, we are still friends today, she and I, 50 years later.

In high school, I was serious about psychology. In the summer after tenth grade I did a project on the effects of distractions on mental-test performance. I discovered that neither of two distractions I created-a car headlamp shining in your eyes, a metronome-interfered with performance relative to a quiet control condition-but the third distraction, listening to the Beatles playing "She's Got the Devil in Her Heart," improved performance. I rediscovered the Hawthorne effect.

In eleventh grade, my physics performance was on a downhill trajectory, so I created a physics aptitude test. It worked! My high school used it for a few years to identify students for honors physics classes. I was really excited now.

\section{Always follow your passions, even if others are not supporting you in doing so. Following your passions will lead to your doing your best work.}

Something else happened in high school that was rather unfortunate. My father abandoned the family. I don't talk about this much. I'm not sure I've ever written of it. He had been leaving for longer and longer periods of time and then one day he just left for good, never to return and never to make any effort again to see my older brother Paul or me. His leaving was a shock to the system. On the one hand, I was used to doing things myself. Neither of my parents even graduated from high school so they were not in a position to give me much academic help. But like every child, I counted on my parents for emotional support; my father was gone, however. My mother went into something of a funk and became, shall we say, self-preoccupied, which is perhaps understandable considering the circumstances. I felt like my life was falling apart, an experience that would happen more than once in my future. But I did learn a lesson.

\section{Life will hand out some really bad blows. People who succeed are often no smarter than others; they just are more resilient in the face of these blows.}

I went to Yale as an undergraduate, wanting to study intelligence. I got off to a really bad start. My first semester I took introduction to psychology with Bob Crowder, and got a $\mathrm{C}$ in the course. He referred to it as a gift. Regrettably, I deserved it-I just was never much of a memorizer. I later took an upper level course from Bob in which I received an $\mathrm{A}$, and he was instrumental in bringing me back to Yale as an assistant professor. Despite my initial bad performance in his class, I have the fondest memories of him and regretted very much his early passing. 
No one in the Yale department at the time was studying, or seemed remotely interested in, intelligence. So I did some papers on intelligence but ended up working first with Professor Alexander Wearing, and when he left to move to the University of Melbourne, I worked with Professor Endel Tulving. Tulving was a wonderful adviser, although his interests and mine were less than a perfect match. I worked with him on the measurement of subjective organization in free recall (Sternberg \& Tulving, 1977) and on negative transfer in part-whole and whole-part free recall. Don't ask me what this negative transfer is-I don't have room here to describe it. Tulving was arguing that whereas everyone else in the field was saying that more repetitions of a word always improved memory for that word, he could show that more repetitions under certain circumstances actually could damage recall. He was right, about that and many other things, especially in his skepticism of conventional beliefs.

When a lot of people are sure of something, that doesn't make it right. Often, it is evidence that this something is wrong because no one is bothering to question it.

I graduated from Yale in 3 $\frac{1}{2}$ years and inbetween undergraduate and graduate school I expanded what had been a part-time job into a full-time job, becoming a special assistant to the dean of undergraduate admissions at Yale. I published two studies resulting from my work on admissions at Yale. One study was on how greatly to reduce the time allocated to applicants who were certainly going to be either accepted or rejected. The other study was a cost-benefit analysis of the Yale admissions office interview (Sternberg, 1972, 1973). I showed that the main use of the interview was public relations for the interviewees, especially because they thought they did substantially better in the interviews than they actually had.

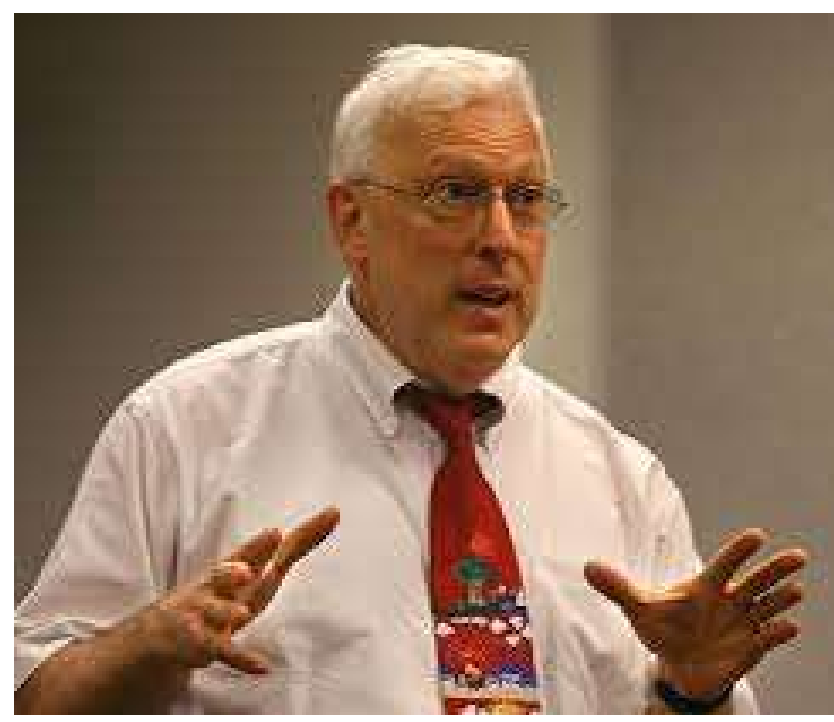

I went on to graduate school to work with Professor Gordon Bower at Stanford, another wonderful adviser. At the beginning of the first year, Gordon held a party at his house for his new students. We were all lined up and asked what we wanted to explore in our research. I was toward the end of the line-maybe at the end, I don't remember. Anyway, Gordon was doing research on semantic memory in those days and everyone knew it. So one by one the students in front of me in line, when asked what they wanted to do, said "semantic memory." They didn't get to Stanford for nothing: They knew where the rewards lay. I didn't want to study semantic memory; I wanted to study intelligence. A coward at the end of the line, when asked what he wanted to study, would have said "semantic memory." A courageous person of course would have said "intelligence." The last thing I would want is for you to think I was nothing but a big coward. When they got to me, I said "semantic memory." Yup, I was a coward. I'm still ashamed of myself, 44 years later.

\section{There will be times in your career where events occur that show who you really are, and whether you are courageous or cowardly. Act with courage, not with cowardice.}


One other distinctly memorable event occurred in that first year at Stanford. The chair of the department was leading a firstyear proseminar in which each psychologydepartment faculty member would give a talk on his or her own work. The chair announced that, at the end of the course, there would be a final examination. I raised my hand and said that I could not understand why there would be a final, as it seemed odd to organize knowledge by which particular Stanford professors created that knowledge. The chair did not respond well and a few days later, seeing me near the elevator, asked whether I finally had figured out "how things work around here." I smiled. If I could relive that year, I would say the same thing again. P.S. The exam later was canceled. He decided not to give it.

\section{There will be great pressure on} you to follow the norms of academia, no matter how silly or even ridiculous they are. You may or may not follow them, but in the end, remember you need to live with yourself.

During my first year, I studied transfer in part-whole and whole-part free recall, ending up with a great first-year project (Sternberg \& Bower, 1974). During my first year of graduate school, Endel Tulving visited at the Center for Advanced Study in the Behavioral Sciences. It was late spring. Endel invited me one day to come and see him. While I was there, I met some other eminent scientists at the Center. One of them asked me what I planned to do in my future research. I explained that my firstyear project had gone really well (and it had), but now I was not sure of what I could do next. I saw the scientists stare at me, seeming to feel sorry for me that, at 23 years old, I already was a one-idea person. I'd had a good idea for my first-year project and that appeared to be it. I felt humiliated. Later that summer I came up with the idea for what would become my dissertation, and
I was more than a one-idea guy after all. But I did learn a lesson from the experience.

You may well go through periods in your life when you just are not sure what to do next. Don't rush into the next thing just to relieve the anxiety of feeling lost. Wait for an idea that truly excites you.

My dissertation was on human intelligence, in particular, the role of analogical reasoning in human intelligence (Sternberg, 1977a, 1977b). The results came out really well. In retrospect, I am tremendously grateful to Gordon Bower for supporting my work on this dissertation. It really had nothing to do with his interests. I learned one of Gordon's secrets to having had so many highly successful students.

\section{If you want your students to succeed, let them do research on what excites them, whether or not it is what excites you.}

I had no idea at the time how generous Gordon's support was. Since then, I have seen so many selfish faculty members who will advise graduate students only if the students do what the faculty members tell them to do. I was very lucky with both my undergraduate and graduate advisers.

In my third year at Stanford, I started doing job interviews. I interviewed at Michigan, Yale, and Illinois. I got job offers from the latter two. Michigan was my first interview. It did not go great. It started off poorly when I learned that, although I had told the organizer I was allergic to dogs, dinner had been arranged at the home of a faculty member who had two large hairy dogs. Although the faculty member's wife had already cooked the dinner, it had to be called off. It went no better when I gave my job talk. A young scruffy looking guy in the audience asked what I thought was a stupid question. I answered with a mild put-down. It was too bad for me that the chair of the 
search committee looked so young and scruffy. That was the end of that job.

\section{- Always treat all colleagues with respect, no matter how much you may question them or their work. Apply the Golden Rule of treating others the way you would want them to treat you.}

I was torn between going to the University of Illinois and Yale. I ended up going back to Yale as an assistant professor, probably because of nostalgia for my undergraduate days. Yale was a tough place in those times - the tenure rate for junior faculty was only 10\%. But I figured that it would be a good place to spend five or six years. I was really excited about going back and very much enjoyed my time at Yale. There were some great professors, and my informal mentor during my assistant-professor days, Wendell Garner, was exceptional. But the pressure of tenure was always there.

In my third year at Yale, I received a phone call from a faculty member at another prestigious institution asking me what it would take to get me to leave Yale and go to his institution. I said "tenure" and he said "no problem." I was thrilled! I knew that the chances of my remaining at Yale were poor and that the quicker I got out, the less I would have to worry. So I told my chair about the job offer and they started to consider me for (very) early tenure at Yale. Well, it's a long story, but it turned out the call was not a job offer. The professor who called was not the chair, no formal offer was made, and nothing was in writing. So I had to go through the humiliation of asking Yale to withdraw from considering me for tenure that year. I felt like being swallowed by a large pit. But my colleagues were very nice to me and I got tenure a couple of years later. Meanwhile, I learned another valuable lesson:

\footnotetext{
- If you do not have it in writing, you don't have it.
}

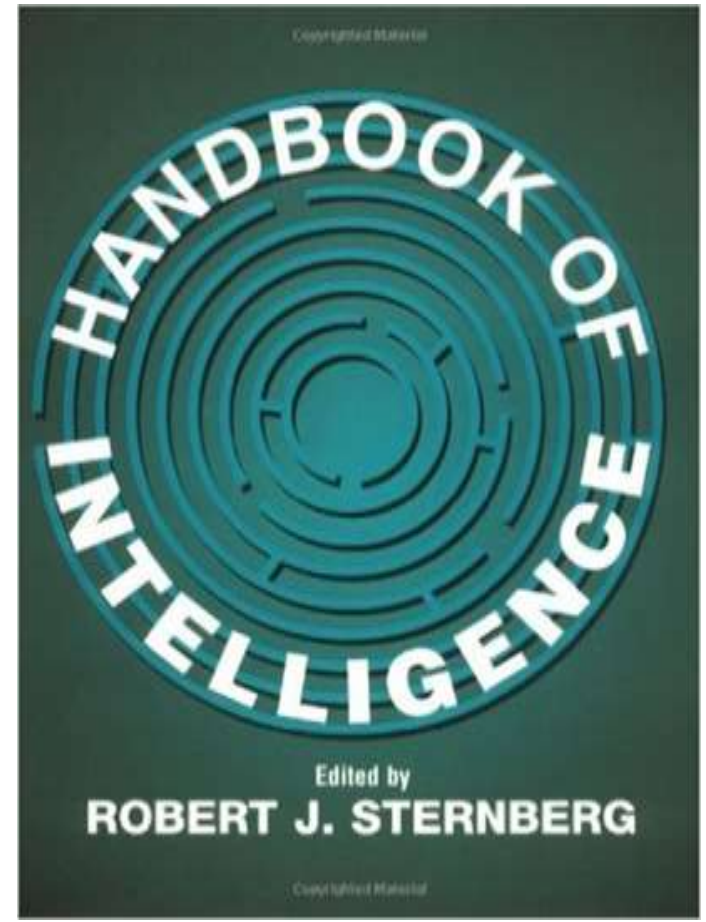

I was doing research on what I called the "componential analysis of human intelligence" (e.g., Sternberg, 1979, 1980, 1983). In those days, I had hopes that my work might somehow become immortal. I had no idea how over-reaching a hope that was! At the time, my thought was that what was wrong with traditional psychometric research was that it looked at person variance rather than stimulus variance (Sternberg, 1985a). The work was going well: I was analyzing performance on a variety of tasks found on intelligence tests and discovering that underlying performance on these tasks was a series of identifiable information-processing components. For example, I could take a task like an analogical-reasoning or a linearsyllogism task and specify in some detail the components of information processing, the strategies into which the components combined, and the mental representations on which the components and strategies acted. I could also specify how much time each component took to execute and how likely it was to lead to error (Sternberg, 1978). My approach at the time was in contrast to that of Earl Hunt, who was using a cognitive-correlates rather than a 
cognitive-components approach (Hunt, Lunneborg, \& Lewis, 1975). His goal was to take standard tasks in cognitive psychology, which had not been used to measure intelligence, and to look at correlations of those tasks and elements of those tasks with performances on standard tests of intelligence. An even greater contrast was with the work of Arthur Jensen (1998), who was studying mental speed as revealed through choice reaction time as a basis for intelligence. Reviews of these and many other approaches can be found in Sternberg (1982, 2000a) and in Sternberg \& Kaufman (2011).

I had my whole career mapped out in my head-how I was going to study one task after another task after another task and do componential analyses of them. Even then, the thought of such a career practically bored the pants off of me. But as it turned out, my career was to take a different turn.

My interactions with particular graduate students led me to believe that, no matter how well I analyzed the components of various information-processing tasks, I would never truly understand intelligence through that kind of work because there is more to intelligence than is measured just by the kinds of tasks found on IQ tests (Sternberg, 1984c). In particular, these interactions convinced me that there were three aspects to intelligence-analytical, creative, and practical - and that conventional intelligence tests only measured the first two (Sternberg, 1984b). So I abandoned my plans to analyze the components of more and more and more tasks.

\section{Plan ahead but not too far ahead because a good research career does not simply build on your early research, but rather builds on the inadequacies of that early research as well.}

In my fifth year, a tenure slot opened at Yale. It was an international competition. Two of my assistant professor colleagues at

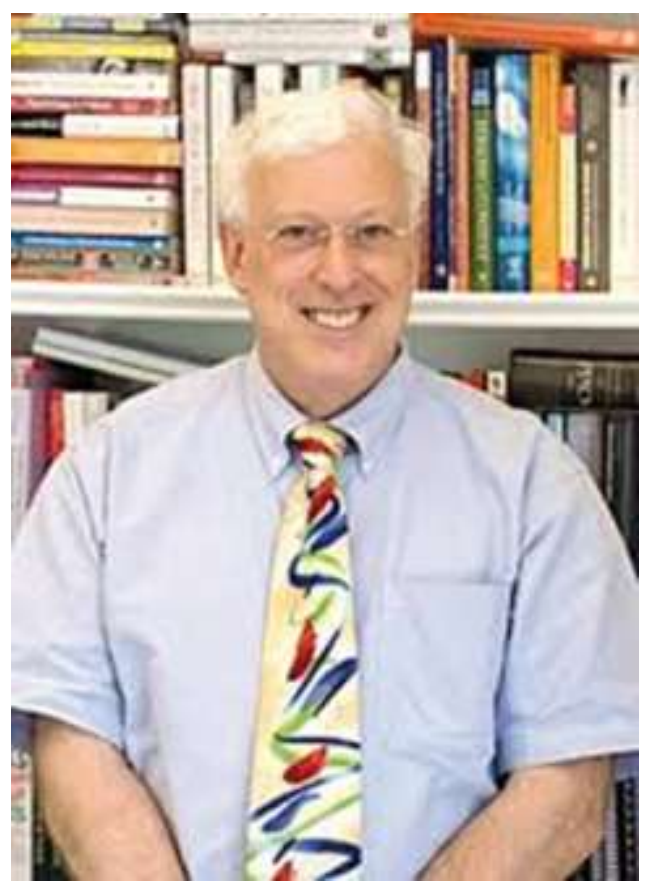

Yale were also competing for the slot. I was reasonably good friends with one of them. The other one was acting strangely toward me. So one day, when he was in my office, I said to him that he should realize we assistant professors were all in this together, and that we should all be friends and face the challenge together. He replied that we could not be friends because we were competing. He left when he did not get the slot and our relations have never been great. I have been surprised in my career by people's willingness to personalize things.

My position on the broad nature of intelligence puts me at odds with many scholars who view intelligence more narrowly. There is one scholar in particular who, over the course of the years, has been attacking not only my work, but also me personally. I cannot imagine why that person would find it necessary to do this.
Do not personalize professional disagreements. Life is too short and the person who loses most from your anger is not the target of your anger, but you personally, because you diminish yourself as a person. 
After the period when my goal was to analyze this task and that, I moved to the next period of my career, in which I tried to develop and validate my triarchic theory of human intelligence, which maintains that creative and practical abilities are at least as important as analytical ones, and that all abilities are modifiable (Detterman \& Sternberg, 1982; Okagaki \& Sternberg, 1993; Sternberg, 1985b). Moreover, practical abilities are key in many aspects of everyday life (Sternberg \& Smith, 1985). During this period I was also building up my lab and working with many wonderful graduate students. We showed, at least to our satisfaction, that creative and practical intelligence are relatively distinct from each other and from analytical intelligence. In other words, someone could have high IQ or SAT/ACT scores, and yet have little common sense or little creativity.

Conversely, someone with high common sense might not look particularly adept on a conventional test of intelligence.

As time went on, the theory of successful intelligence superseded the older triarchic theory (Sternberg, 1997c). It was an elaboration on the earlier theory, placing more emphasis on the fact that being successful in your use of intelligence is not

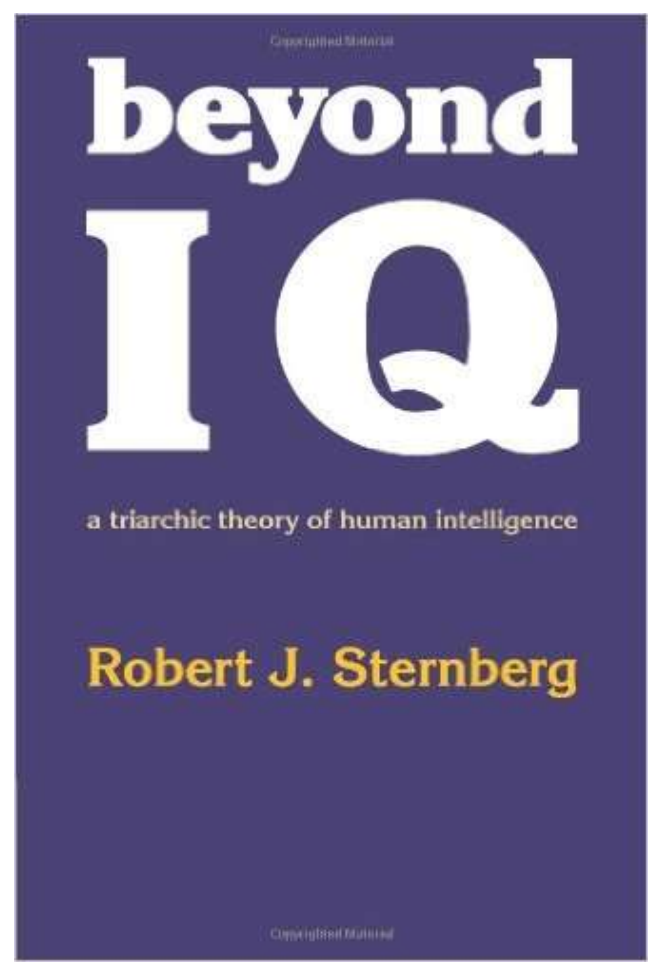

just a matter of having more of analytical, creative, and practical abilities. Rather, it is a matter of recognizing your own strengths and weaknesses, and then of finding ways to capitalize on your strengths and correct or compensate for your weaknesses (Sternberg, 2005). In my earlier work, I had focused too much on the abilities themselves and not enough on how they were leveraged in everyday life.

During this period, I was traveling much of the time and holding down multiple grants at once. I was very happy in my career. I was less happy in my personal life and my wife and I eventually split up. We had met when we were 16 years old and probably we were not a match made in heaven. We had joint custody of our children, Seth and Sara (mentioned earlier), but I never saw them as much as I would have liked to-or should have. My personal life was pretty much a mess, as it has been for much of my life before I met Karin, with whom I had the triplets. But by the age of 66, I have learned one thing I think is crucially important.

\section{- Never put your personal life on hold for your career. It doesn't "hold" and your kids will grow up, with you or without you. When you get older, you will realize, inevitably, that the most important thing in your life is your family.}

This lesson struck me not only as a result of my own personal life but as a result of some other people's. By the time I was in my 30s, some of the faculty members whom I had known for many years at Yale, even when I was an undergraduate, had fallen into ill health. The trend accelerated when I reached my 40s. I would visit them and learned that my other colleagues seemed not to be visiting them. I was struck by how alone my colleagues who were in failing health were, unless they had their family to care for them. All the awards and academies and bold publications no longer counted. What was left were family and the stray 
occasional visitor such as myself. Your publications won't take care of you when you are older; they will not love you and you will not love them. You will hardly remember them.

\section{- If you put your family relationships on hold, you will have much less to show for your life than you should. Put your family first.}

At this point, I had moved much of my research out of the laboratory. We were doing research on business executive, sales people, military officers, teachers-all kinds of people whom we never realistically could study in the lab (Sternberg et al., 2000). What was bothering me more and more was that psychology and I seemed to be moving in opposite directions. There always were two directions in which I thought the field might move-more toward the inside (the brain, the lab) or more toward the outside (the ecological context, the everyday world). The two directions are not mutually exclusive. But psychology has moved more toward the inside. I wish it had moved at least in both directions so that the ecological side of things could be better represented than it is today (Sternberg, 1984a).

One day, while I was in my office, I received a surprising call. A Ministry for the Development of Intelligence had been formed in Venezuela and the minister was looking for collaborators from abroad who would work with him and his ministry to improve the intelligence of the Venezuelan population. I accepted the invitation to visit, and out of it came a project with college students to improve their thinking skills. It was a great project, and led me to learn to speak Spanish, which today I speak fluently. (In secondary school, I had studied Latin and then French.)

The project resulted in a book (Sternberg, 1986a; Sternberg, Kaufman,
\& Grigorenko, 2008) but it never resulted in any formal data. Well into the project, there were elections in Venezuela and the opposition, as part of its campaign platform, ridiculed the projects supported by the government that allegedly would improve people's intelligence. The opposition party won and my project, as well as the other projects, experienced a sudden death. I felt it was a great shame. But again, there was a lesson to be learned.

- Much as scientists might detest the fact, scientific funding always takes place within a political context. Funding can change just as rapidly as the political context of the funding changes.

Much later, I would again see the result of changes in political currents, but the next time the change would be in the United States. I will say more about that later.

\section{Applied Intelligence}

Robert J. Sternberg James C. Kaufman Elena L. Grigorenko

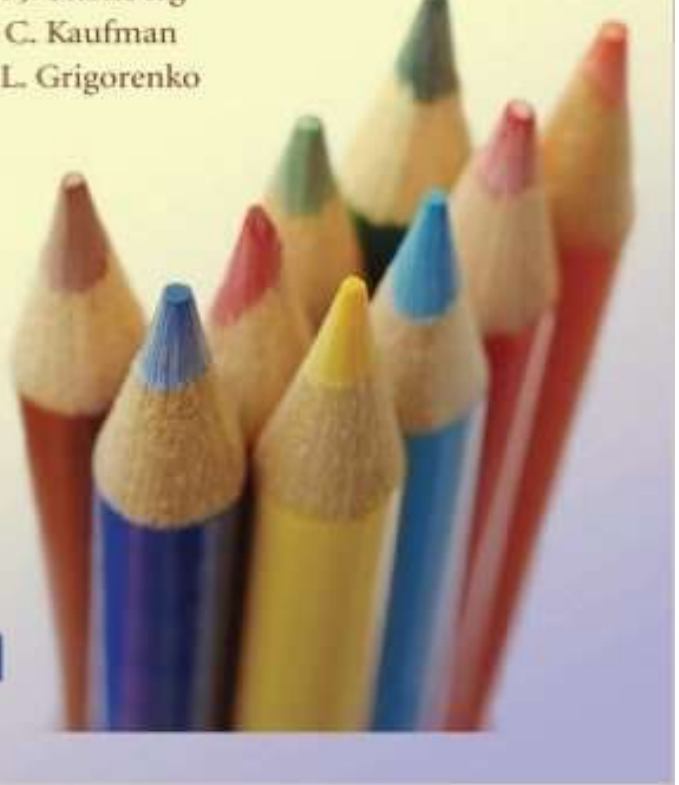


Although the Venezuela project did not result in an opportunity to improve the intelligence of Venezuelan students, another opportunity seemed to arise. I was interested in using the theory not only to improve intelligence but also to improve school achievement. So we did a large study showing that if students were taught in a way that enabled them optimally to capitalize on their strongest ability, their school achievement would increase. We found that to be the case (Sternberg, Grigorenko, Ferrari, \& Clinkenbeard, 1999). We also showed that "triarchic" teaching improved school achievement (Grigorenko, Jarvin, \& Sternberg, 2002; Sternberg, Torff, \& Grigorenko, 1998a, 1998b), although it was hard to get this improvement if we upscaled and lost control of the fidelity of the teaching training and implementations of the theory (Sternberg et al., 2014). I should note that these were early collaborations with Elena Grigorenko, whose superb collaborations proved invaluable to me throughout many years of my career, and I hope to her as well!

\section{* Putting theories into practice can be devilishly difficult, especially when one tries to upscale the implementation and loses control of crucial aspects of the implementation.}

Another opportunity came out of the blue, this time one that yielded many interesting empirical investigations. I was invited, I'm not sure why, to attend a meeting that would be discussing a project to improve the health of people in developing countries through medical interventions. A part of the project was to investigate not only the people's physical health, but also their psychological health and especially their cognitive abilities. In one project in Jamaica, we showed that medical interventions to combat parasitic illnesses could improve children's mental functioning (Sternberg et al., 1997). I eventually became enmeshed in this project, with Don Bundy of Oxford as principal investigator, investigating the cognitive effects of anti-parasitic medications. Later we broadened our focus and began studying differences in the meaning of intelligence across various cultures. For example, in one culture, academic performance might be considered to be an important indicator of intelligence, but in another culture academic performance might be seen as of little importance or even be seen as a negative indicator of intelligence, as in, Who cares about how a child performs in school (Sternberg, 2004, 2007; Sternberg \& Grigorenko, 2004a)? In one of our studies, we found academic intelligence, on the one hand, and practical intelligence for adaptation in the culture (rural Kenya), on the other, to be negatively correlated (Sternberg et al., 2001).

In another study, we found that dynamic testing - testing in which children learn at the time they are tested-could give a very different impression of a child's abilities from the impression given by conventional intelligence tests. We further found that people's conceptions of intelligence differ widely across cultures (Grigorenko et al., 2001; Sternberg, 2004). Especially in the developing world, academic intelligence was much less highly valued than it is in the developed world and has a different meaning (Sternberg, Conway, Ketron, \& Bernstein, 1980; Sternberg, 1985e).

Even among scientists, there are very different metaphors for understanding intelligence (Sternberg, 1985d, 1990). Theories of intelligence differ not just in how they specify intelligence, but in the underlying assumptions about what intelligence is-whether it is biological or anthropological or sociological or whatever.

This work made me realize just how culturally limited our intelligence testing has been, including the testing that I had done in much of my own work. That work assumed that whatever Western investigators mean by intelligence, the rest of the world had to agree with us and work with our definitions. But they don't. And the result is that, because we so rarely look at enculturation processes, our research is far 
more impoverished conceptually than we realize (Sternberg \& Grigorenko, 2000).

Even in our own country, different groups have different implicit theories of intelligence - that is, beliefs about what intelligence is. Teachers may have implicit theories that differ from parents. The result can be that the teachers reward behavior that is quite different from that believed to be intelligent by children's parents (Sternberg, 1987b).

\section{We take to be universal results that may be barely or not at all applicable in cultures differing radically, or even only slightly, from our own.}

Doing research abroad may sound exotic and in some ways it was: we worked on five continents. But in other ways it can be remarkably distressing. Before a trip to India, I started taking an anti-malarial drug, mefloquine. It seemed innocuous enough. It wasn't. For more than a year after I took it, I had fairly loud ringing in my yearstinnitus. The ringing eventually went away but something must have changed inside my ears because ever since then, I have been susceptible to ringing in my ears. For example, I can take only very low doses of certain pain medications because at higher doses I get ringing.

Another spectacular opportunity arose when my colleagues and I got an opportunity, through an Army Research Institute contract, to collaborate with professors at the United States Military Academy at West Point on studies of practical intelligence for leadership. Those studies, too, yielded interesting results. Again and again, we found that practical intelligence is largely distinct from academic intelligence (Hedlund et al., 2003; Sternberg et al., 2000).

The smartest people academically may have little or even no discernible common sense. Do not let academic smarts substitute for the common sense you need to get through life.

The best part of the work on practical intelligence, however, was the collegiality of the professors we worked with, especially Colonel George Forsythe. I have been in many organizations that have some kind of deep-seated fear of the military, but in the many years I was funded by the Office of Naval Research and then the US Army Research Institute, I found many collaborators of superb character and truly impressive research credentials.

Although during this time, most of my research was on intelligence, I found myself branching out into other fields. In every instance, I studied phenomena, like intelligence, that had been problematical in my life. One of the areas into which I branched out was love (Sternberg, 1986b, 1987a, 1997a; 1998b, 1998c; Sternberg \& Barnes, 1985; Sternberg \& Grajek, 1984; Sternberg, Hojjat, \& Barnes, 2001), and then hate (Sternberg, 2003b; Sternberg \& K. Sternberg, 2008). Although I developed the theory of hate, it was my wife, Karin Sternberg (then Weis), who in her dissertation actually tested it empirically (Weis, 2006). My initial work on love occurred when I was in a failing relationship and just as I once had hoped to understand why I had done poorly on intelligence tests, I now found myself wanting to understand why I was doing so poorly in my love life!

My theory of love went through several stages but eventually it turned into what I came to call a "duplex theory of love" (Sternberg, 2006). The first part of the theory was a triangular theory of love, according to which love comprises three elements: intimacy, passion, and commitment. Those three elements combine to yield different kinds of love. For example, intimacy and passion form romantic love, passion and commitment in the absence of intimacy form fatuous or foolish love, and all three elements form complete or consummate love. The idea for 


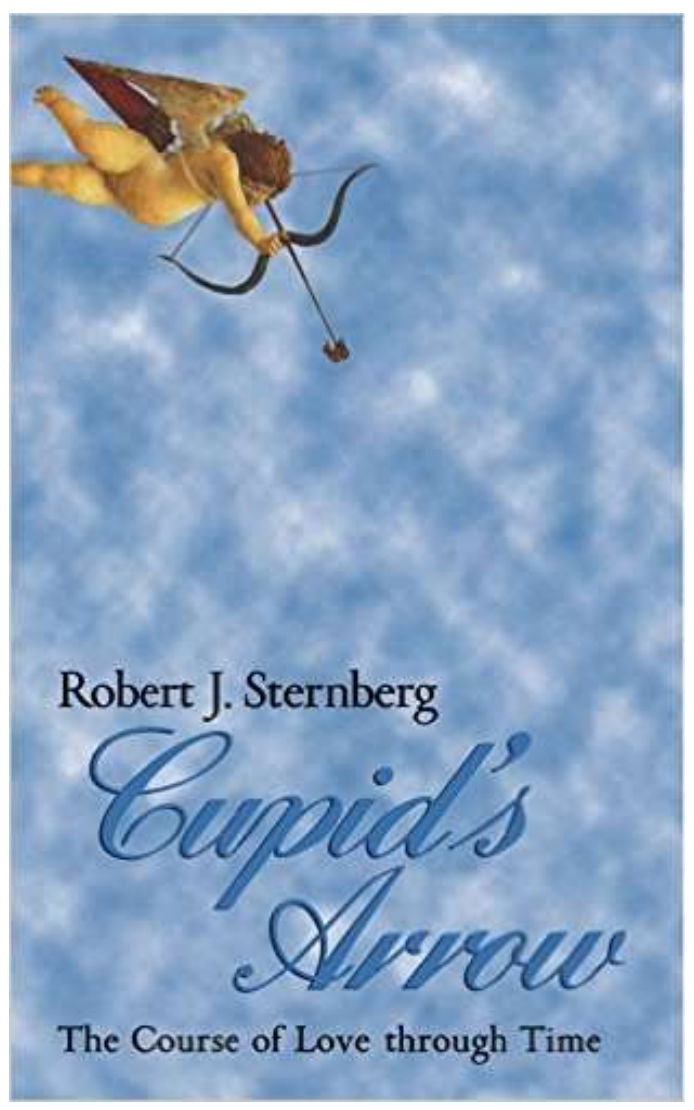

this theory, like the idea for the triarchic theory of intelligence, came from my life experience, in particular, relationships I had been in that emphasized intimacy, passion, or commitment.

\section{* If you don't have each of intimacy, passion, and commitment in your intimate relationship, you are missing an important ingredient of a successful and happy relationship.}

The other part of the theory is the theory of love as a story, according to which love is always based on stories that we form as a result of our interactions with the worldthrough watching parental relationships, relationships in movies, relationships in books, relationships of friends, and so forth (Sternberg, 1995b). There are roughly two dozen common stories. Some examples are a fairy-tale story (a prince and a princess); a travel story (two people traveling together down the many roads of life); a business story (two business partners who treat the relationship like an enterprise); and a horror story (a perpetrator and a victim). Through my work on love I came to know Ellen Berscheid, who at the time was a professor at the University of Minnesota. Although we have seen each other, I believe, only once or twice, I have come to consider her one of my very best friends.

\section{Your love relationship only can be as good as the story underlying it. If you have a bad story (a horror story, a police story, a pornography story), your relationship will be built on that story and will never be better than the story on which it is based.}

At the same time I was working on love I was working as well on conflict resolution (Sternberg \& Dobson, 1987; Sternberg \& Soriano, 1984). I did a few studies on conflict resolution and the results were the same. People have preferred styles of conflict resolution and the people who resolve conflicts most effectively are those who are willing to step down - that is, to work toward reducing conflict rather than showing how tough or bellicose they can be.

\section{When you have conflicts with others, try to step them down rather than step them up. You are more likely to have success in resolving the conflicts. The strategy only works, however, if all parties genuinely want to resolve the conflicts.}

I also took to doing work in two other areas-creativity and thinking styles. With Todd Lubart, then a Yale graduate student but now a professor of psychology at the University of Paris V, I developed the investment theory of creativity, according to which creative people are like good investors, buying low and selling high, except in the world of ideas rather than the world of financial investments (Sternberg, 
2003a; Sternberg \& Lubart, 1991, 1992, 1995). Creative people, therefore, defy the crowd and often end up paying for it when the crowd does not like ideas that defy it.

\section{* Although academics are supposed to appreciate creativity, they often feel threatened by it. If you have highly creative ideas, do not expect a warm reception- rather, expect the opposition that always has confronted truly creative ideas.}

The other line of research that consumed me for a while was on thinking styles. I formulated what I called a theory of mental self-government, according to which people govern themselves much as governments manage societies (Sternberg, 1997b; Sternberg \& Grigorenko, 2001; Sternberg, Grigorenko, \& Zhang, 2008; Zhang \& Sternberg, 2006). People have different preferred forms of mental self-government. For example, some people are more

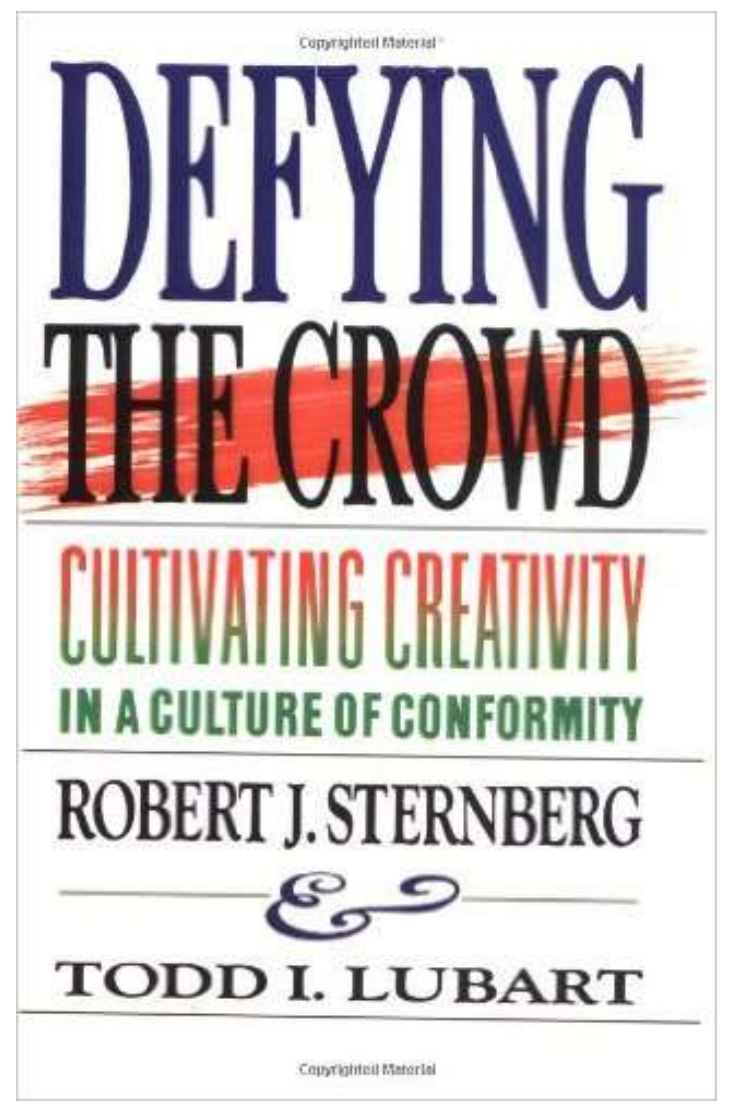

"legislative," preferring to do things their own way. Other people are more "executive," preferring to be told what to do. Other people are more "judicial," liking to judge others and their work. There are 13 different styles, which coexist in varying degrees. We found that people differ in their styles, and that preferred styles may or may not correspond to their strengths and abilities. That is, someone who likes to come up with his or her own ideas (a legislative person) is not necessarily creative, and a judicial person who likes to analyze things is not necessarily strong in analytical abilities (Sternberg, 1985c; Zhang \& Sternberg, 2009). We found that styles predict school performance incrementally over scores on tests of abilities. My invaluable collaborators in this area have been Elena Grigorenko and Li-fang Zhang.

- People's styles-their preferred ways of doing things-do not always match their abilities, and they may achieve less than they otherwise might have.

In a propulsion theory of creative contributions, I further proposed that there can be various kinds of creativity (Sternberg, 1999a; Sternberg, Kaufman, \& Pretz, 2002).

The kind that makes people most comfortable is what I called a "forward incrementation," that is, a small step forward in the direction a field is already going. People are much less comfortable with "redirections" of fields, or "reinitiations" that essentially try to start a field over. So academics may like creativity, but they tend to like most the creativity that does not threaten their worldview and, by inference, them!

Everyone likes creativity except when they feel threatened by it, and the more creative an idea, the more likely people are to feel threatened by it. 
I also extended my work on creativity to organizations, proposing a theory of organizational modifiability (Sternberg, $2000 \mathrm{~b}$, in press). According to the theory, organizations differ in their modifiability, or potential creativity as organizations. A "rusted iron" organization is stuck in the past and is both unable and unwilling to move forward. An "opal" organization wants to look like it is moving at the same time it is staying wholly in place. And a "diamond in the rough" organization wants to change and become better. There are roughly eight different types of organizations, differing in their potential for meaningful change.

\section{Even very prestigious organizations can be "rusted iron" organizations, stuck in antiquated ways of doing things and unable to move into the future because they are unwilling or unable to change.}

At the same time that creativity can be a tremendous boon to the world, it also can be used for nefarious and even evil purposes (Sternberg, 2010a). I came to realize that creativity in itself was not necessarily "good." Eventually I came to believe that the most important cognitive attribute for a person is neither intelligence nor creativity but rather wisdom.

This realization led to the earlier formulation of my balance theory of wisdom (Sternberg, 1998a), according to which wisdom is the application of one's abilities and knowledge to achieve a common good, balancing one's own, others', and higher interests, over the longas well as the short-term, through the infusion of positive ethical values.

According to the theory, you have to be somewhat intelligent to be wise but you do not have to be wise to be intelligent, and most intelligent people are not wise. Indeed, intelligent people are particularly susceptible to being foolish because they think that, with their intelligence, they could not possibly be foolish (Sternberg, 2002, 2004).

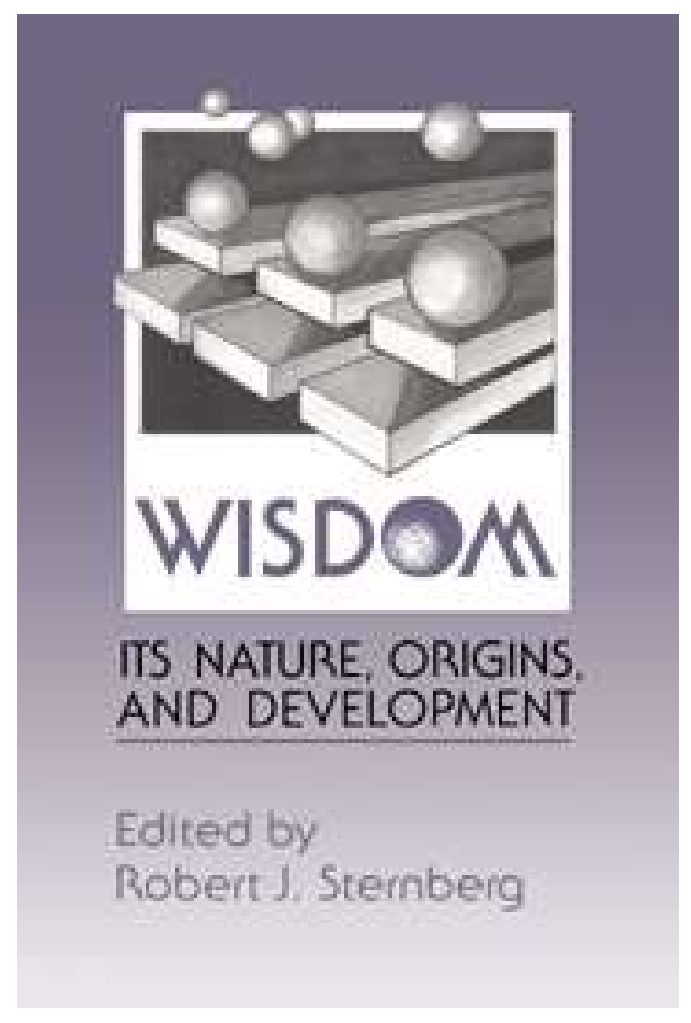

Thus, they are unprotected from their own failings. Smart people are particularly susceptible to cognitive fallacies of unrealistic optimism regarding the value of their own ideas, egocentrism, false sense of omniscience, false sense of omnipotence, false sense of invulnerability, and ethical disengagement_-believing that ethics apply to others but not to themselves.

Often, intelligent people behave foolishly because they think they are incapable of foolish behavior and therefore do not guard against it.

The balance theory of wisdom led me to work on leadership and my formulation of WICS - wisdom, intelligence, creativity, synthesized (Sternberg, 2003c, 2003d, 2008). I came to realize that good and effective leaders are wise, intelligent (academically and practically), and creative, but that leaders today often lack for many if not most of these features, distinguishing themselves more by their ambitions than by their skills in leadership. Some, like Ted Cruz and Donald Trump, manage to attain positions of leadership through their high 
academic intelligence accompanied by less than stellar wisdom-based skills.

Meanwhile, my career at Yale had taken a new turn. In 2000, I started a center, the Center for the Psychology of Abilities, Competencies, and Expertise (PACE Center). The Center was entirely grantsupported. We got a number of large grants and moved into our own building. We spent five years there. Eventually, we had roughly three dozen people working at the Center. It was a wonderful period of professional life. But I came to realize how difficult it is to support a center entirely on soft money, especially when I was the only professor at the Center. Our most successful project, I believe, was on admissions.

You'll recall I started my work life in admissions. I now came to see admissions as a way to test the theory of successful intelligence. In a project called "Rainbow," my collaborators and I devised tests of analytical, creative, and practical abilities, which could be used in college admissions. We administered them to high school seniors and college freshmen across the country. We found that we could double prediction of first-year college GPA, substantially reduce ethnic group differences relative to the SAT, and increase applicant satisfaction with the assessments over the SAT. The results were great, were published as the lead article in the best journal in the field, and received some publicity (Sternberg $\&$ the Rainbow Project Collaborators, 2005, 2006). Then the organization that funded the work, a large testing company, cut off our funding and refused to renew it, saying that we could not upscale what we had done.

\footnotetext{
We often admit talented analysts to our top universities who test well and get good grades but they may lack creativity, common sense, and wisdom. The universities sometimes are administered by people with the very same attributes.
}

This posed a bit of a career crisis for me. I had hoped to spend much of the rest of my career developing the college-admissions measures and also seeing them used for real college admissions. It now looked like that was not about to happen. Moreover, at this point, I had been at Yale for 34 years and was feeling a need for a change. So I decided to apply for deanships.

This move was a departure from what I had done before, but not a total departure. In 2003, I served as president of the American Psychological Association. I had gone into the job expecting it to be challenging but not particularly enjoyable. I really was doing it as a service to the field. To my surprise, I enjoyed the job. The challenges were indeed considerable and I had one or two board members who were exceptionally difficult to deal with. But at this point, I decided that, to my surprise, I enjoyed academic leadership, and that maybe someday I would make a career change and give it a try.

Needless to say, when I applied for deanships, universities were crawling to my doorstep, begging me to take a deanship at their particular university. Actually, that's
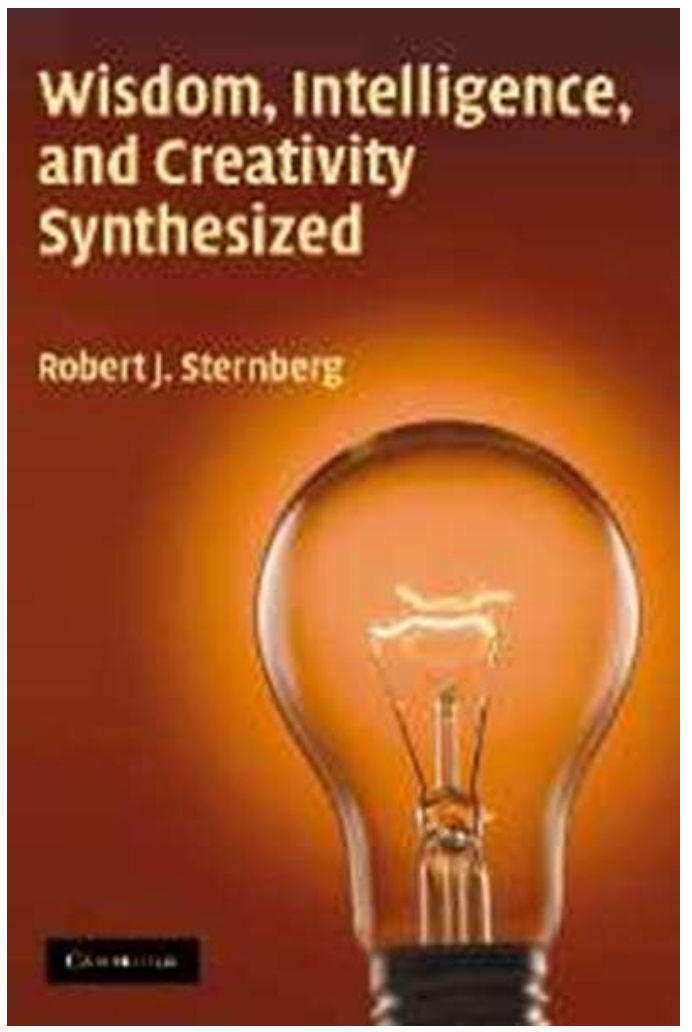
not true at all. I completed so many applications and received so many rejections that, contrary to my own advice in everything I ever had written on rejection, I gave up. I decided it just wasn't going to happen. At that point, I received two job offers and moved from Yale to Tufts. I moved to Boston and started out on an adventure into the unknown. That was one of the best periods of my life, largely because it was there that Karin and I got married. We have since had a story-book marriage-something I would have thought was impossible for me.

I was not a paper-pusher by nature.

Rather, I went into administration to accomplish some specific goals. One was the implementation of a new admissions system, which came to be called "Kaleidoscope." We implemented tests of analytical, creative, practical, and wisdombased skills. Wisdom had not been measured in the Rainbow Project. Where did it come from?

I had become dissatisfied with my triarchic theory of intelligence precisely because it was mute on the subject of wisdom (Sternberg, 2003d). Some might think that practical intelligence is closely related to wisdom, but it is not. Donald Trump is an example of someone of high practical intelligence but who shows an extreme lack of wisdom. A salesman who sells defective used cars, or defective political policies, may be practically intelligent without being wise. So at this point, I augmented the theory of successful intelligence to include wisdom. And thus wisdom was measured in the Kaleidoscope Project. Lee Coffin, Dean of Undergraduate Admissions at Tufts, was an invaluable collaborator in this project.

The results of the Kaleidoscope Project, administered over a period of a number of years (and still used at Tufts) were excellent. We increased prediction of academic and personal success and also reduced ethnic-group differences. Furthermore, we also increased prediction of success in extracurricular activities. Numbers of applications increased, especially from underrepresented minorities, and our admission statistics for underrepresented minorities improved (Sternberg, 2010). We believe the results for minorities were especially important, given the great importance our society attaches to matters of race (Sternberg, Grigorenko, \& Kidd, 2005).

The other major initiative at Tufts was for a teaching center, the Center for the Enhancement of Learning and Teaching (CELT). The idea was to teach professors how to teach for analytical, creative, practical, and wise thinking. We had success in recruiting professors to learn how to teach better, partly by offering extrinsic rewards_-either a teaching reduction or a stipend. I wish it would have been possible to recruit professors just on the basis of their desire to improve their teaching-but that didn't happen.

I stayed at Tufts as a dean for five years-until 2010. At that point, two things happened. First, I became a member of the Board of Directors of the Federation of Associations in Behavioral and Brain Sciences (FABBS), as president-elect, then president, then past-president. I spent six years on the board. Also, I moved to Oklahoma State University as Provost.

Although I spent only three years at Oklahoma State, they probably were the happiest of my career. For one thing, my personal life was the best it had ever been and my time at Oklahoma State saw the birth of our triplets. For another thing, I loved the atmosphere of the place. There were a lot of first-generation college students, like me, and going to college made a huge difference to their lives, as it had to mine. At places like Yale and Tufts, the students really could have gone anywhere and, in many cases, nowhere and still succeeded by virtue of the assistance their parents were able to give them. At Oklahoma State, the students were truly on their own. Third, the president, Burns Hargis, was terrific_-everything you could hope for in a boss. And finally, I really liked the people I met in Oklahoma. 
At Oklahoma State, we implemented Panorama, a project something like Kaleidoscope that was suitable for the population at the university. The results were very promising. I did a lot of writing and editing during those years in addition to my responsibilities as provost. But although I liked Oklahoma, my wife Karin did not, and we both felt that the state was too conservative for us and especially for raising children. So we moved on to the University of Wyoming, where I served as president.

Moving to Wyoming was the worst mistake of both my professional and personal lives, and I've made many bad mistakes! We were a total mismatch to the state and the university. We probably could not have found a place that would have been a worse fit. Whereas I had expected Wyoming to be like Oklahoma, it was nothing like it except for being very conservative. I proposed many initiatives, which were met with disapproval. I sacked some administrators, which also was met with disapproval. In less than a year, I resigned and found myself jobless for the first time in my adult life. We were eager to get out - they were eager for us to get outand so I hoped that I could get a new job in a hurry!

I did. Within a few months of resigning the presidency, I began as a professor of Human Development at Cornell University, which is where I am now. We have enjoyed living in the Ithaca area and Cornell has been a good fit for me.

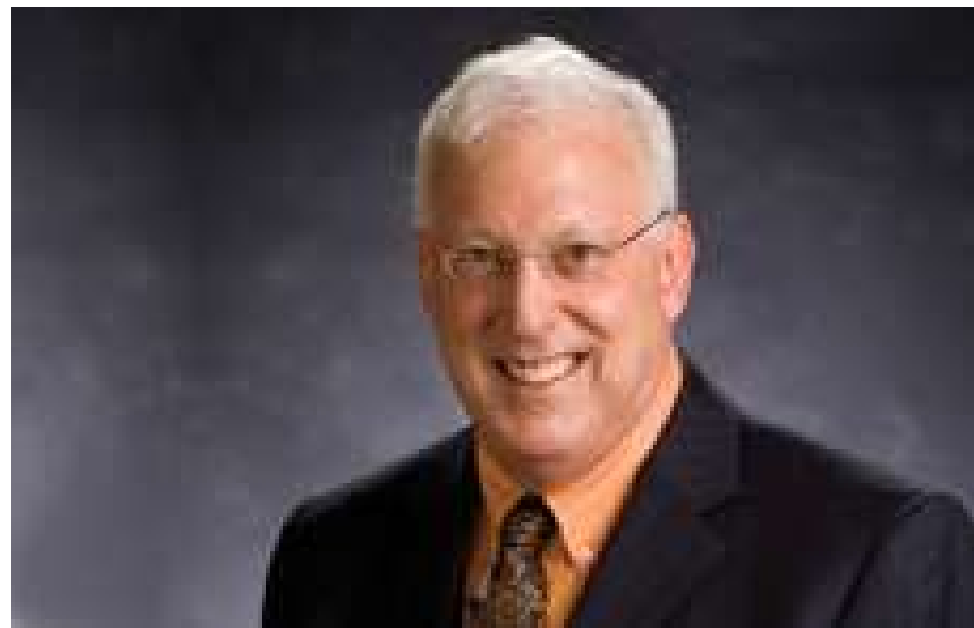

I restarted my flagging research program and quickly became involved in a large number of projects - on graduate admissions, medical-school admissions, jealousy, and ethics.

In recent years, I have become particularly interested in the study of ethics, having published a model of ethical reasoning (Sternberg, 2012, 2015a, 2015b) and having co-edited a book on the topic (Sternberg \& Fiske, 2015). I am convinced that the world would be a much better place if we did not just hope that people would learn to think and behave ethically, but rather if we gave them models for ethical thinking and behavior. I have also become very interested in how my ideas can be applied to university education (Sternberg, in press), and I still have hopes that some of the ideas may be put into practice, although probably not in my lifetime!

Susan Fiske, Don Foss, and I assembled a volume of short essays by individuals identified by objective means as in the top 200 psychologists of the modern era (Sternberg, Fiske, \& Foss, in press). My family and I have been happy at Cornell (where Karin is currently a research associate), and we expect to stay here for a long time. Someday we will retire and we have aspirations to move back to Boston at that time. But that is many years away and who knows?

In most respects, I've had a good life. It has been full of mistakes and as a result of my lack of wisdom in many different domains of life. I grew up in an uneducated, unwise household, and in many respects I carried the lack of wisdom into my adulthood. I hope that over the years I have gained some of the wisdom I lacked when I was younger. I did not attain as much professional success as I had hoped for and have had little success to date in getting any of my ideas successfully implemented in schools. 
There are two other scholars who I think have had more success than I in getting their work implemented. Their goals have been in many ways quite similar although certainly not identical to mine. One is Howard Gardner (2011). His theory of multiple intelligences has been put into practice in many schools. Although we have some disagreements regarding his theory, obviously, the theory has seen widespread use. The other is Joseph Renzulli (Renzulli \& Gubbins, 2009). I have collaborated with both Gardner and Renzulli. Indeed, Renzulli and I were involved in the National Research Center for the Gifted and Talented for many years, with him as director and me as an associate director. I have worked in the field of giftedness (e.g., Sternberg, 1981; Sternberg \& Grigorenko, 2004b; Sternberg \& Zhang, 1995), but I believe Renzulli has revolutionized a field that had been stuck in a time warp, namely, gifted education.

On the positive side, my work has been cited many times (over 108,000 times, $\mathrm{h}$ index of 159), I've received 13 honorary doctorates, and I have won many awards, including both top awards of the Association for Psychological Science. I am a member of the National Academy of Education and the American Academy of Arts and Sciences. In earlier days, I felt badly that I never achieved the success of my mentors-Tulving, Bower, Garnerthat I had hoped for. But these days, I realize that I have the kind of personality that, regardless of what happens, will always be dissatisfied with my accomplishments.

I have so many people to whom to whom I am grateful in my career that I scarcely know where to start. My wife, Karin Sternberg, has transformed my life, along with my five children-Seth, Sara, Samuel, Brittany, and Melody. My academic mentors-Endel Tulving, Gordon Bower, and Wendell Garner-certainly taught me things I never would have learned on my own and helped take me to where I am today (wherever that may be!). Burns Hargis, President of Oklahoma State University when I was there, was a terrific mentor for academic leadership. My career would have gone practically nowhere without the collaboration of the 60 or so graduate students and postdocs I have mentored, some of whom have been named in this essay. Karin Sternberg and I also have collaborated on many important projects. And I have made some really terrific friends over the years (some of them former students) - for example, Anne Beall, Ellen Berscheid, Chuck Brainerd, Steve Ceci, Janet Davidson, James Kaufman, Linda Jarvin, Todd Lubart, David Preiss, Sally Reis, Joe Renzulli, Roddy Roediger, Richard Wagner, Wendy Williams - who have been influential at many points in my career and life.

\section{If you do not reach your initial goals, don't feel distressed. The goals were probably the wrong ones anyway.}

If I could do my career over again, there probably is not much I would have done differently. Certainly I never would have gone to the University of Wyoming as president - that was a match made in hell. I might have tried some administrative tasks earlier in my career. But on the whole, I look back on many fine years, and then just a few that were not so great.

I especially would recommend editing to my colleagues. I've edited three journals-Psychological Bulletin, The APA Review of Books: Contemporary Psychology, and Perspectives on Psychological Science-and I think editing journals (and books, of which I've edited well over 100) is a great way to learn about the field. Another great way to learn about the field is to write textbooks. I've written several, two of which, in collaboration with Karin Sternberg, have gone past five editions (Sternberg \& Sternberg, 2017, in press). One of the textbooks (Sternberg, 1995a) was closely based on my theory of successful intelligence, and was intended to put the theory into practice in the learning of psychology, just as another textbook was intended to teach teachers how to teach 
triarchically (Sternberg \& Grigorenko, 2007).

\section{Editing journals and books and writing textbooks are activities that help you learn new things about psychology over your entire life.}

As I've become older, I have come to realize that my bid for immortality actually has succeeded, just not in the way I initially planned. My work, like the work of most scholars who fall short of Piaget or Freud, will not be immortal. But I will be immortal through my students and through my five children and their children and their children onward. The secret sauce to achieving immortality is the form God intended for us - the ability to create a new generation of life and to have the greatest possible pride in the accomplishments of those who will follow.

You want to be immortal? Teach students; have children!

\section{References}

Detterman, D. K., \& Sternberg, R. J. (Eds.). (1982). How and how much can intelligence be increased? Norwood, NJ: Ablex.

Gardner, H. (2011). Frames of mind: The theory of multiple intelligences. New York: Basic.

Grigorenko, E. L., Geissler, P. W., Prince, R., Okatcha, F., Nokes, C., Kenny, D. A., Bundy, D. A., \& Sternberg, R. J. (2001). The organization of Luo conceptions of intelligence: A study of implicit theories in a Kenyan village. International Journal of Behavioral Development, 25(4), 367-378.

Grigorenko, E. L., Jarvin, L., \& Sternberg, R. J. (2002). School-based tests of the triarchic theory of intelligence: Three settings, three samples, three syllabi. Contemporary Educational Psychology, 27, 167-208.

Hedlund, J., Forsythe, G. B., Horvath, J. A., Williams, W. M., Snook, S., \& Sternberg, R. J. (2003). Identifying and assessing tacit knowledge: Understanding the practical intelligence of military leaders. Leadership Quarterly, 14, 117-140.

Hunt, E. B., Lunneberg, C., \& Lewis, J. (1975). What does it mean to be high verbal? Cognitive Psychology, 7, 194-227.

Jensen, A. R. (1998). The g factor. Westport, CT: Praeger-Greenwood.

Okagaki, L., \& Sternberg, R. J. (1993). Putting the distance into students' hands: Practical intelligence for school. In R. R. Cocking \& K. A. Renninger (Eds.), The development and meaning of psychological distance (pp. 237-253). Hillsdale, NJ: Lawrence Erlbaum.

Renzulli, J., \& Gubbins, E. J. (2009). Systems and models for developing programs for the gifted and talented $\left(2^{\text {nd }}\right.$ Ed.). Waco, TX: Prufrock.

Sternberg, R. J. (1972). A decision rule to facilitate the undergraduate admissions process. College and University, 48, 48-53.

Sternberg, R. J. (1973). Cost-benefit analysis of the Yale admissions office interview. College and University, 48, 154-164.

Sternberg, R. J. (1977a). Component processes in analogical reasoning. Psychological Review, 84, 353-378.

Sternberg, R. J. (1977b). Intelligence, information processing, and analogical reasoning: The componential analysis of human abilities. Hillsdale, NJ: Lawrence Erlbaum. 
Sternberg, R. J. (1978). Componential investigations of human intelligence. In A. Lesgold, J. Pellegrino, S. Fokkema, \& R. Glaser (Eds.), Cognitive psychology and instruction (pp. 277298). New York: Plenum.

Sternberg, R. J. (1979). The nature of mental abilities. American Psychologist, 34, 214-230.

Sternberg, R. J. (1980). Sketch of a componential subtheory of human intelligence. Behavioral and Brain Sciences, 3, 573-584.

Sternberg, R. J. (1981). A componential theory of intellectual giftedness. Gifted Child Quarterly, 25, 86-93.

Sternberg, R. J. (Ed.). (1982). Handbook of buman intelligence. New York: Cambridge University Press.

Sternberg, R. J. (1983). Components of human intelligence. Cognition, 15, 1-48.

Sternberg, R. J. (1984a). A contextualist view of the nature of intelligence. International Journal of Psychology, 19, 307-334.

Sternberg, R. J. (1984b). Toward a triarchic theory of human intelligence. Behavioral and Brain Sciences, 7, 269-287.

Sternberg, R. J. (1984c). What should intelligence tests test? Implications of a triarchic theory of intelligence for intelligence testing. Educational Researcher, 13, 5-15.

Sternberg, R. J. (1985a). Applying componential analysis to the study of individual differences in cognitive skills. In C. Reynolds \& V. Willson (Eds.), Methodological and statistical advances in the study of individual differences. New York: Plenum.

Sternberg, R. J. (1985b). Beyond IQ: A triarchic theory of human intelligence. New York: Cambridge University Press.

Sternberg, R. J. (1985c). Critical thinking: Its nature, measurement, and improvement. In F. R. Link (Ed.), Essays on the intellect (pp. 45-65). Alexandria, VA: Association for Supervision and Curriculum Development.

Sternberg, R. J. (1985d). Human intelligence: The model is the message. Science, 230, 1111-1118.

Sternberg, R. J. (1985e). Implicit theories of intelligence, creativity, and wisdom. Journal of Personality and Social Psychology, 49(3), 607-627.

Sternberg, R. J. (1986a). Intelligence applied: Understanding and increasing your intellectual skills. San Diego, CA: Harcourt Brace Jovanovich.

Sternberg, R. J. (1986b). A triangular theory of love. Psychological Review, 93, 119-135.

Sternberg, R. J. (1987a). Liking versus loving: A comparative evaluation of theories. Psychological Bulletin, 102, 331-345.

Sternberg, R. J. (1987b). Second game: A school's-eye view of intelligence. In J. A. Langer (Ed.), Language, literacy, and culture: Issues of society and schooling (pp. 23-48). Norwood, NJ: Ablex.

Sternberg, R. J. (1990). Metaphors of mind: Conceptions of the nature of intelligence. New York: Cambridge University Press.

Sternberg, R. J. (1995a). In search of the human mind. Orlando, FL: Harcourt Brace College Publishers.

Sternberg, R. J. (1995b). Love as a story. Journal of Social and Personal Relationships, 12(4), 541-546.

Sternberg, R. J. (1997a). Construct validation of a triangular love scale. European Journal of Social Psychology, 27(3), 313-335.

Sternberg, R. J. (1997b). Thinking styles. New York: Cambridge University Press.

Sternberg, R. J. (1997c). The triarchic theory of intelligence. In D. P. Flanagan, J. L. Genshaft, \&

P. L. Harrison (Eds.), Contemporary intellectual assessment: Theories, tests, and issues (pp. 92-104).

New York: Guilford Press.

Sternberg, R. J. (1998a) A balance theory of wisdom. Review of General Psychology, 2, 347-365.

Sternberg, R. J. (1998b). Cupid's arrow: The course of love through time. New York: Cambridge University Press.

Sternberg, R. J. (1998c). Love is a story. New York: Oxford University Press. 
Sternberg, R. J. (1999a). A propulsion model of types of creative contributions. Review of General Psychology, 3, 83-100.

Sternberg, R. J. (Ed.). (2000a). Handbook of intelligence. New York: Cambridge University Press.

Sternberg, R. J. (2000b). Making school reform work: A "mineralogical" theory of school modifiability.

Bloomington, IN: Phi Delta Kappa Educational Foundation.

Sternberg, R. J. (Ed.). (2002). Why smart people can be so stupid. New Haven: Yale University Press.

Sternberg, R. J. (2003a). Creative thinking in the classroom. Scandinavian Journal of Educational Research, 47(3), 326-338.

Sternberg, R. J. (2003b). A duplex theory of hate: Development and application to terrorism, massacres, and genocide. Review of General Psychology. 7(3), 299-328.

Sternberg, R. J. (2003c). WICS: A model for leadership in organizations. Academy of Management Learning \& Education, 2, 386-401.

Sternberg, R. J. (2003d). Wisdom, intelligence, and creativity synthesized. New York: Cambridge University Press.

Sternberg, R. J. (2004). Why smart people can be so foolish. European Psychologist, 9(3), 145-150.

Sternberg, R. J. (2005). The theory of successful intelligence. Interamerican Journal of Psychology, 39(2), 189-202.

Sternberg, R. J. (2006). A duplex theory of love. In R. J. Sternberg \& K. Weis (Eds.), The new psychology of love (pp. 184-199). New Haven, CT: Yale University Press.

Sternberg, R. J. (2007). Intelligence and culture. In S. Kitayama \& D. Cohen (Eds.), Handbook of cultural psychology (pp. 547-568). New York: Guilford Press.

Sternberg, R. J. (2008). The WICS approach to leadership: Stories of leadership and the structures and processes that support them. The Leadership Quarterly, 19(3), 360-371.

Sternberg, R. J. (2010a). College admissions for the 21st century. Cambridge, MA: Harvard University Press.

Sternberg, R. J. (2010b). The dark side of creativity and how to combat it. In D. H. Cropley, A. J. Cropley, J. C. Kaufman, \& M. A. Runco (Eds.), The dark side of creativity (pp. 316-328). New York: Cambridge University Press.

Sternberg, R. J. (2012). A model for ethical reasoning. Review of General Psychology, 16, 319-326.

Sternberg, R. J. (2015a). Epilogue: Why is ethical behavior challenging? A model of ethical reasoning. In R. J. Sternberg \& S. T. Fiske (Eds.), Ethical challenges in the behavioral and brain sciences (pp. 219-226). New York: Cambridge University Press.

Sternberg, R. J. (2015b). Ethical impotence. Journal of College and Character, 16, 180-185, DOI:10.1080/2194587X.2015.1057154.

Sternberg, R. J. (in press). What universities can be. Ithaca, NY: Cornell University Press.

Sternberg, R. J., \& Barnes, M. (1985). Real and ideal others in romantic relationships: Is four a crowd? Journal of Personality and Social Psychology, 49, 1586-1608.

Sternberg, R. J., \& Bower, G. H. (1974). Transfer in part-whole and whole-part free recall: A comparative evaluation of theories. Journal of Verbal Learning and Verbal Behavior, 13, 1-26.

Sternberg, R. J., \& Dobson, D. M. (1987). Resolving interpersonal conflicts: An analysis of stylistic consistency. Journal of Personality and Social Psychology, 52, 794-812.

Sternberg, R. J., \& Fiske, S. E. (Eds.) (2015). Ethical challenges in the behavioral and brain sciences: Case studies and commentaries. New York: Cambridge University Press.

Sternberg, R. J., Fiske, S. T., \& Foss, D. J. (Eds.) (in press). Scientists making a difference: The greatest living behavioral and brain scientists talk about their most important contributions. New York: Cambridge University Press.

Sternberg, R. J., Forsythe, G. B., Hedlund, J., Horvath, J., Snook, S., Williams, W. M., Wagner, R. K., \& Grigorenko, E. L. (2000). Practical intelligence in everyday life. New York: Cambridge University Press. 
Sternberg, R. J., \& Grajek, S. (1984). The nature of love. Journal of Personality and Social Psychology, 47, 312-329.

Sternberg, R. J., \& Grigorenko E. L. (2000). Ability testing across cultures. In L. A. Suzuki, J. G. Ponterotto, \& P. J. Meller (Eds.), The handbook of multicultural assessment: Clinical, psychological and educational applications (pp. 335-358). San Francisco: Jossey-Bass Publishers.

Sternberg, R. J., \& Grigorenko, E. L. (2001). A capsule history of theory and research on styles. In R. J. Sternberg, \& L. F. Zhang (Eds.), Perspectives on thinking, learning and cognitive styles (pp. 1-21). Mahwah, NJ: Lawrence Erlbaum Associates.

Sternberg, R. J., \& Grigorenko, E. L. (2004a). Intelligence and culture: how culture shapes what intelligence means, and the implications for a science of well-being. Philosophical Transaction: Biological Sciences, 359(1449), 1427-1434.

Sternberg, R. J., \& Grigorenko, E. L., (2004b) Learning disabilities, giftedness, and gifted/LD. In T. M. Newman, \& R. J. Sternberg. (Eds.) Students with both gifts and learning disabilities (pp. 17-29). Boston: Kluwer Academic Publishers.

Sternberg, R. J., \& Grigorenko, E. L. (2007). Teaching for successful intelligence (2nd ed.). Thousand Oaks, CA: Corwin Press

Sternberg, R. J., Grigorenko, E. L., Ferrari, M., \& Clinkenbeard, P. (1999). A triarchic analysis of an aptitude-treatment interaction. European Journal of Psychological Assessment, 15(1), 1-11.

Sternberg, R. J., Grigorenko, E. L., \& Zhang, L.-F. (2008). Styles of learning and thinking matter in instruction and assessment. Perspectives on Psychological Science, 3(6), 486-506.

Sternberg, R. J., Grigorenko, E. L., \& Kidd, K. K. (2005). Intelligence, race, and genetics. American Psychologist, 60(1), 46-59.

Sternberg, R. J., Hojjat, M., \& Barnes, M. L. (2001). Empirical aspects of a theory of love as a story. European Journal of Personality, 15(3), 199-218.

Sternberg, R. J., Jarvin, L., Birney, D., Naples, A., Stemler, S., Newman, T., . . . Grigorenko, E. L. (2014). Testing the theory of successful intelligence in teaching grade 4 language arts, mathematics, and science. Journal of Educational Psychology, 106, 881-899.

Sternberg, R. J., \& Kaufman, S. B. (Eds.) (2011). Cambridge handbook of intelligence. New York: Cambridge University Press.

Sternberg, R. J., Kaufman, J. C., \& Grigorenko, E. L. (2008). Applied intelligence. New York: Cambridge University Press.

Sternberg, R. J., Kaufman, J. C., \& Pretz, J. E. (2002). The creativity conundrum: A propulsion model of kinds of creative contributions. New York: Psychology Press.

Sternberg, R. J., \& Lubart, T. I. (1991). An investment theory of creativity and its development. Human Development, 34(1), 1-31.

Sternberg, R. J., \& Lubart, T. I. (1992). Buy low and sell high: An investment approach to creativity. Current Directions in Psychological Science, 1(1), 1-5.

Sternberg, R. J., \& Lubart, T. I. (1995). Defying the crowd: Cultivating creativity in a culture of conformity. New York: Free Press.

Sternberg, R. J., \& Smith, C. (1985). Social intelligence and decoding skills in nonverbal communication. Social Cognition, 2, 168-192.

Sternberg, R. J., Nokes, K., Geissler, P. W., Prince, R., Okatcha, F., Bundy, D. A., \& Grigorenko, E. L. (2001). The relationship between academic and practical intelligence: A case study in Kenya. Intelligence, 29, 401-418.

Sternberg, R. J., Powell, C., McGrane, P. A., \& McGregor, S. (1997). Effects of a parasitic infection on cognitive functioning. Journal of Experimental Psychology: Applied, 3, 67-76.

Sternberg, R. J., \& the Rainbow Project Collaborators (2005). Augmenting the SAT through assessments of analytical, practical, and creative skills. In W. Camara \& E. Kimmel (Eds.). Choosing students: Higher education admission tools for the 21 $1^{\text {st }}$ century (pp. 159-176). Mahwah, NJ: Lawrence Erlbaum. 
Sternberg, R. J., \& The Rainbow Project Collaborators. (2006). The Rainbow Project: Enhancing the SAT through assessments of analytical, practical and creative skills. Intelligence, 344), 321-350.

Sternberg, R. J., \& Soriano, L. J. (1984). Styles of conflict resolution. Journal of Personality and Social Psychology, 47, 115-126.

Sternberg, R. J., \& Sternberg, K. (2008). The nature of hate. New York: Cambridge University Press.

Sternberg, R. J., \& Sternberg, K. (2017). Cognitive psychology ( $7^{\text {th }}$ ed.). Boston, MA: Cengage.

Sternberg, R. J., \& Sternberg, K. (in press). The psychologist's companion ( $6^{\text {th }}$ ed.). New York: Cambridge University Press.

Sternberg, R. J., \& Tulving, E. (1977). The measurement of subjective organization in free recall. Psychological Bulletin, 84, 539-556.

Sternberg, R. J., \& Zhang, L. F. (1995). What do we mean by "giftedness"? A pentagonal implicit theory. Gifted Child Quarterly, 39(2), 88-94.

Weis, K. (2006). Explorations of the duplex theory of hate. Berlin: Logos Verlag.

Zhang, L. F., \& Sternberg, R. J. (2006). The nature of intellectual styles. Mahwah, N.J.: Lawrence Erlbaum.

Zhang, L.-F., \& Sternberg, R. J. (2009). Intellectual styles and creativity. In T. Rickards, M.A. Runco, \& S.Moger (Eds.) The Routledge companion to creativity (pp. 256-266). New York: Routledge. 


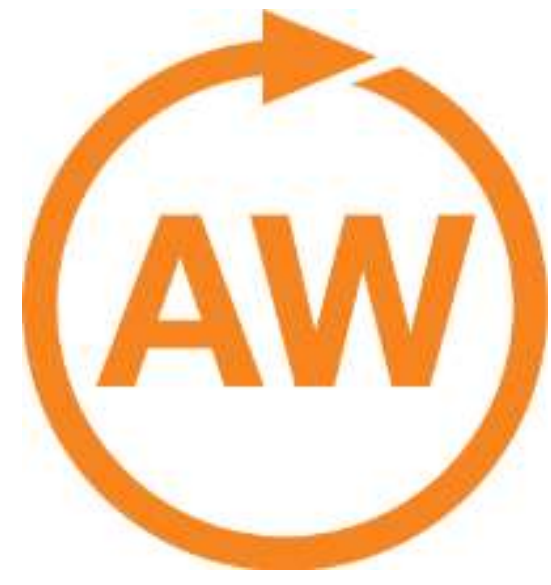

\section{About Acquired Wisdom}

This collection began with an invitation to one of the editors, Sigmund Tobias, from Norman Shapiro a former colleague at the City College of New York (CCNY). Shapiro invited retired CCNY faculty members to prepare manuscripts describing what they learned during their College careers that could be of value to new appointees and former colleagues. It seemed to us that a project describing the experiences of internationally known and distinguished researchers in Educational Psychology and Educational Research would be of benefit to many colleagues, especially younger ones entering those disciplines. We decided to include senior scholars in the fields of adult learning and training because, although often neglected by educational researchers, their work is quite relevant to our fields and graduate students could find productive and gainful positions in that area.
Junior faculty and grad students in Educational Psychology, Educational Research, and related disciplines, could learn much from the experiences of senior researchers. Doctoral students are exposed to courses or seminars about history of the discipline as well as the field's overarching purposes and its important contributors. .

A second audience for this project include the practitioners and researchers in disciplines represented by the chapter authors. This audience could learn from the experiences of eminent researchers- how their experiences shaped their work, and what they see as their major contributionsand readers might relate their own work to that of the scholars. Invitations to potential authors were accompanied by Tobias' chapter in this series for illustrative purposes. Authors were advised that they were free to organize their chapters as they saw fit, provided that their manuscripts contained these elements: 1) their perceived major contributions to the discipline, 2) major lessons learned during their careers, 3) their opinions about the personal and 4) situational factors (institutions and other affiliations, colleagues, advisors, and advisees) that stimulated their significant work.

We hope that the contributions of distinguished researchers receive the wide readership they deserve and serves as a resource to the future practitioners and researchers in these fields. 


\section{education review // reseñas educativas \\ a multi-lingual journal of book reviews \\ editors: gustavo e. fischman I \\ melissa cast-brede / gene $v$ glass}

Supported by the Mary Lou Fulton Teachers College, Arizona State University

\section{Acquired Wisdom is \\ Edited by}

Sigmund Tobias

University at Albany

State University of New York
J. D. Fletcher

Institute for Defense Analyses

Alexandria VA
David C. Berliner

Arizona State University

Tempe AZ

\section{Advisory Board Members}

Gustavo Fischman, Arizona State University

Arthur C. Graesser III, Memphis State University

Teresa 1. McCarty, University of California Los Angeles

Kevin Welner, Colorado State University

ఠ

Education Review/Reseñas Educativas/Resenhas Educativas is supported by the edXchange initiative's Scholarly Communications Group at the Mary Lou Fulton Teachers College, Arizona State University. Copyright is retained by the first or sole author, who grants right of first publication to the Education Review. Readers are free to copy, display, and distribute this article, as long as the work is attributed to the author(s) and Education Review, it is distributed for non-commercial purposes only, and no alteration or transformation is made in the work. More details of this Creative Commons license are available at http://creativecommons.org/licenses/by-nc-sa/3.0/. All other uses must be approved by the author(s) or Education Review. Education Review is published by the Scholarly Communications Group of the Mary Lou Fulton Teachers College, Arizona State University.

Connect with Education Review on Facebook (https://www.facebook.com/pages/EducationReview/178358222192644) and on Twitter @EducReview 